\title{
Clinical imaging factors of excellent outcome after thrombolysis in large- vessel stroke: a THRACE subgroup analysis
}

Nolwenn Riou-Comte, ${ }^{1}$ Benjamin Gory, ${ }^{2}$ Marc Soudant (i) ${ }^{3}$ François Zhu, ${ }^{2}$ Yu Xie, ${ }^{2}$ Lisa Humbertjean, ${ }^{1}$ Gioia Mione, ${ }^{1}$ Catherine Oppenheim, ${ }^{4}$ Francis Guillemin, ${ }^{3}$ Serge Bracard, ${ }^{2}$ Sébastien Richard (D) , ${ }^{1}$ on behalf of the THRACE investigators

To cite: Riou-Comte N, Gory B, Soudant M, et al. Clinical imaging factors of excellent outcome after thrombolysis in large-vessel stroke: a THRACE subgroup analysis. Stroke \& Vascular Neurology 2021;0. doi:10.1136/svn-2020-000852

Received 31 December 2020 Revised 9 April 2021 Accepted 14 April 2021
Check for updates

(C) Author(s) (or their employer(s)) 2021. Re-use permitted under CC BY-NC. No commercial re-use. See rights and permissions. Published by BMJ.

${ }^{1}$ Department of NeurologyStroke Unit, CIC-P 1433, INSERMU1116, Université de Lorraine, Nancy Regional University Hospital Center, Nancy, France

${ }^{2}$ Department of Diagnostic and Therapeutic Neuroradiology, INSERM U1254, IADI, Université de Lorraine, Nancy Regional University Hospital Center, Nancy, France

${ }^{3}$ Clinical Investigation CentreClinical Epidemiology 1433, INSERM, Université de Lorraine, Nancy Regional University Hospital Center, Nancy, France ${ }^{4}$ Department of Neuroradiology, INSERM U894, Université Paris-Descartes, Sainte-Anne Hospital, Paris, France

Correspondence to Professor Sébastien Richard; s.richard@chru-nancy.fr

\section{ABSTRACT}

Background For patients with stroke with large-vessel occlusion (LVO), study of factors predicting response to intravenous thrombolysis (IVT) would allow identifying subgroups with high expected gain, and those for whom it could be considered as futile, and even detrimental. From patients included in the Mechanical Thrombectomy After Intravenous Alteplase vs Alteplase Alone After Stroke trial, we investigated clinical-imaging factors associated with optimal response to IVT.

Methods We included patients receiving IVT alone. Excellent outcome was defined by a 3-month modified Rankin Scale (mRS) score $\leq 1$. Clinical-imaging predictors were assessed on multivariate analysis after multiple imputations. The predictive performance of the model was assessed with the $\mathrm{C}$-statistic.

Results Among 247 patients with LVO treated with IVT alone, 77 (31\%) showed 3-month mRS $\leq 1$. Predictors of 3-month $\mathrm{mRS} \leq 1$ were no medical history of hypertension (OR 2.43; 95\% Cl 1.74 to 3.38; $p=0.007$ ); no current smoking (OR 2.76; $95 \% \mathrm{Cl} 1.79$ to 4.26 ; $\mathrm{p}=0.02$ ); onset-toIVT time (OR 0.47 per hour increase; $95 \% \mathrm{Cl} 0.23$ to 0.78 ; $\mathrm{p}=0.003)$; diffusion-weighted imaging (DWI) volume (OR 0.78 per $10 \mathrm{~mL}$ increase; $95 \% \mathrm{Cl} 0.68$ to $0.89 ; \mathrm{p}=0.0004$ ); presence of susceptibility vessel sign (SVS) (OR 7.89; $95 \% \mathrm{Cl} 1.65$ to $37.78 ; \mathrm{p}=0.01$ ) and SVS length (OR 0.87 per $\mathrm{mm}$ increase; $95 \% \mathrm{Cl} 0.80$ to $0.94 ; \mathrm{p}=0.001)$. The prediction models showed a C-statistic $=0.79(95 \% \mathrm{Cl} 0.79$ to 0.80 ).

Conclusions In patients with stroke with anteriorcirculation LVO treated with IVT alone, predictors of excellent outcome at 3 months were no medical history of hypertension or current smoking, reduced onset-to-IVT time, small DWI volume, presence of SVS and short SVS length. These predictive factors could help practitioners in decision-making for IVT implementation in reperfusion strategies, all the more for the drip and ship paradigm. Trial registration number NCT01062698.

\section{INTRODUCTION}

Intravenous thrombolysis (IVT) is a cornerstone in therapeutic strategies for cerebral reperfusion. It allows for early reperfusion in about one-third of patients with acute ischaemic stroke due to large-vessel occlusion (LVO) of anterior circulation. ${ }^{1}$ While mechanical thrombectomy (MT) is mostly performed in comprehensive stroke centres with endovascular capacities, patients may have wide access to IVT treatment in developed stroke networks. Main indications and contraindications have been defined following original studies assessing IVT gain and safety. ${ }^{23}$ Nowadays, both are debated in practice as well as in clinical research. ${ }^{4}$ Then, identification of factors predicting optimal response to IVT or not, would help to define subgroups of patients with LVO for whom high gain is expected or, on the contrary, those with an overriding haemorrhagic risk.

Most studies have explored the association between isolated imaging criteria or clinical findings and response to IVT. ${ }^{5} 6$ Most prediction models for stroke outcome were developed without considering a revascularisation strategy and without identifying patients with $\mathrm{LVO}$ as a poor prognosis subgroup. $^{7}$

From the major trial Mechanical Thrombectomy After Intravenous Alteplase vs Alteplase Alone After Stroke (THRACE), ${ }^{8}$ we sought to determine the clinical and imaging predictors of 3-month excellent outcome after IVT alone in patients with anterior-circulation LVO and to evaluate the predictive performance of early neurological improvement to anticipate this successful response to treatment.

\section{METHODS}

\section{Study population}

The study was a subgroup analysis of the randomised controlled THRACE trial study. ${ }^{8}$ Patients with LVO of the anterior circulation treated with IVT only were included in the present analysis. 


\section{Outcome}

The primary end point was 3-month excellent outcome after IVT alone, defined as a modified Rankin Scale (mRS) score $0-1$ at 3 months.

\section{Clinical and imaging characteristics}

Demographic characteristics (age, sex, vascular risk factors and comorbidities), baseline examination data (blood pressure, heart rate, US National Institutes of Health Stroke Scale (NIHSS) score, glycaemia, temperature), symptom onset to IVT treatment time (OTT), clinical outcomes (24-hour NIHSS score, 3-month mRS score) and imaging characteristics (Alberta Stroke Programme Early CT (ASPECT) score, diffusion-weighted imaging (DWI) ischaemic volume, vascular territory of ischaemia, deep white matter hyperintensities by the FAZEKAS score, susceptibility vessel sign (SVS) or hyper-dense middle cerebral artery sign (HMCAS), SVS or HMCAS length, clot burden score (CBS), thrombus location, FLAIR vascular hyperintensities $(\mathrm{FVH}) / \mathrm{DWI}$ mismatch $^{9}$ and ASPECT-FVH score ${ }^{10}$ ) were extracted from a centralised database.

The NIHSS score improvement from pretreatment to 24-hour examination was defined by the following criteria: (1) a normalised NIHSS score change $(\%)^{11}$; (2) a strong neurological improvement (SNI) defined as 24-hour NIHSS score $\leq 3$; (3) a major neurological improvement (MNI) defined as 24-hour NIHSS score $\leq 1$ or an improvement in NIHSS score $\geq 8$ points; (4) a National Institute of Neurological Disorders and Stroke neurological improvement as an improvement in NIHSS score $\geq 4$ points $^{12}$; (5) NIHSS score improvement of $\geq 25 \%$ at 24 hours and (6) NIHSS score improvement of $\geq 50 \%$ at 24 hours.

\section{Statistical analysis}

All analyses involved using SAS/STAT V.9.3 (SAS Institute, Cary, North Carolina, USA). Continuous variables are described with mean $\pm \mathrm{SD}$ or median $\pm \mathrm{IQR}$ and categorical characteristics with frequency $(\%)$.

Groups of patients presenting 3-month mRS score 0-1 vs 2-6 were compared in terms of clinical, anamnestic and radiological criteria by Student's t-test, Kruskal-Wallis test, $\chi^{2}$ test or Fisher's exact test, as appropriate. After multiple imputation, predictors of excellent outcome after IVT alone were assessed by stepwise multivariable logistic regression analysis (significance level for entry $=0.2$, significance level for removing=0.05), estimating ORs and 95\% CIs. To account for differences between CT and MRI, the imaging methods were considered a nesting covariate for each studied imaging characteristic. Multivariate model performance was assessed by the C-statistic.

Sensitivity, specificity, positive predictive value (PPV), negative predictive value (NPV) and their 95\% CIs for each definition of 24-hour neurological improvement were computed according to 3-month outcome. Associations between 24-hour NIHSS improvement and 3-month outcome were revealed by multivariable logistic regression analysis using crude ORs and after adjustment for the previous predictors of 3-month outcome as well as age, baseline NIHSS score, 24-hour ASPECT score and Safe Implementation of Thrombolysis in Stroke-Monitoring Study haemorrhage classification. ${ }^{13}$ A Bonferroni correction for the inflation of the first-species risk was performed for this second analysis.

\section{RESULTS}

Of the 412 patients included in the THRACE trial, 259 received IVT alone: 208 patients were randomised in the IVT group and 200 actually received IVT alone; 204 patients were randomised in the IVT/MT group and 59 did not receive MT and therefore had IVT alone. Of these

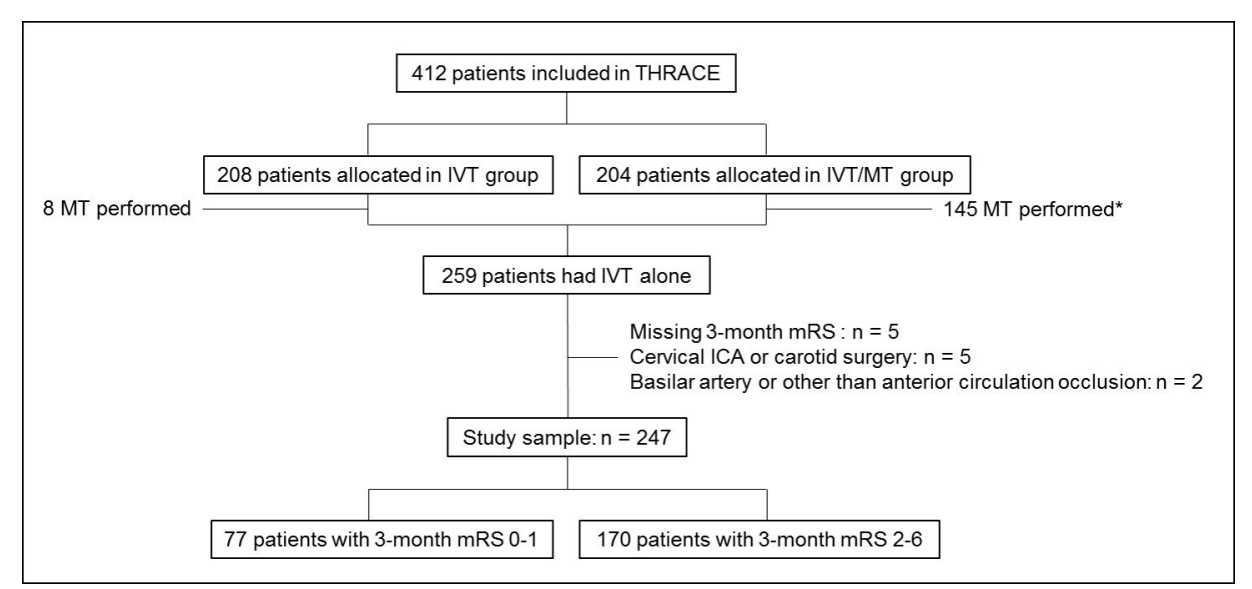

Figure 1 Flow chart. Excellent outcome was defined as a 3-month modified Rankin Scale (mRS) score $\leq 1$. ${ }^{*}$ One of the requirements for mechanical thrombectomy was the absence of neurological improvement $\geq 4$ points between baseline National Institutes of Health Stroke Scale (NIHSS) and NIHSS within 1 hour of IVT. ICA, internal carotid artery occlusion; IVT, intravenous thrombolysis; MT, mechanical thrombectomy; THRACE, Mechanical Thrombectomy After Intravenous Alteplase vs Alteplase Alone After Stroke. 
Table 1 Cohort description and bivariate analysis

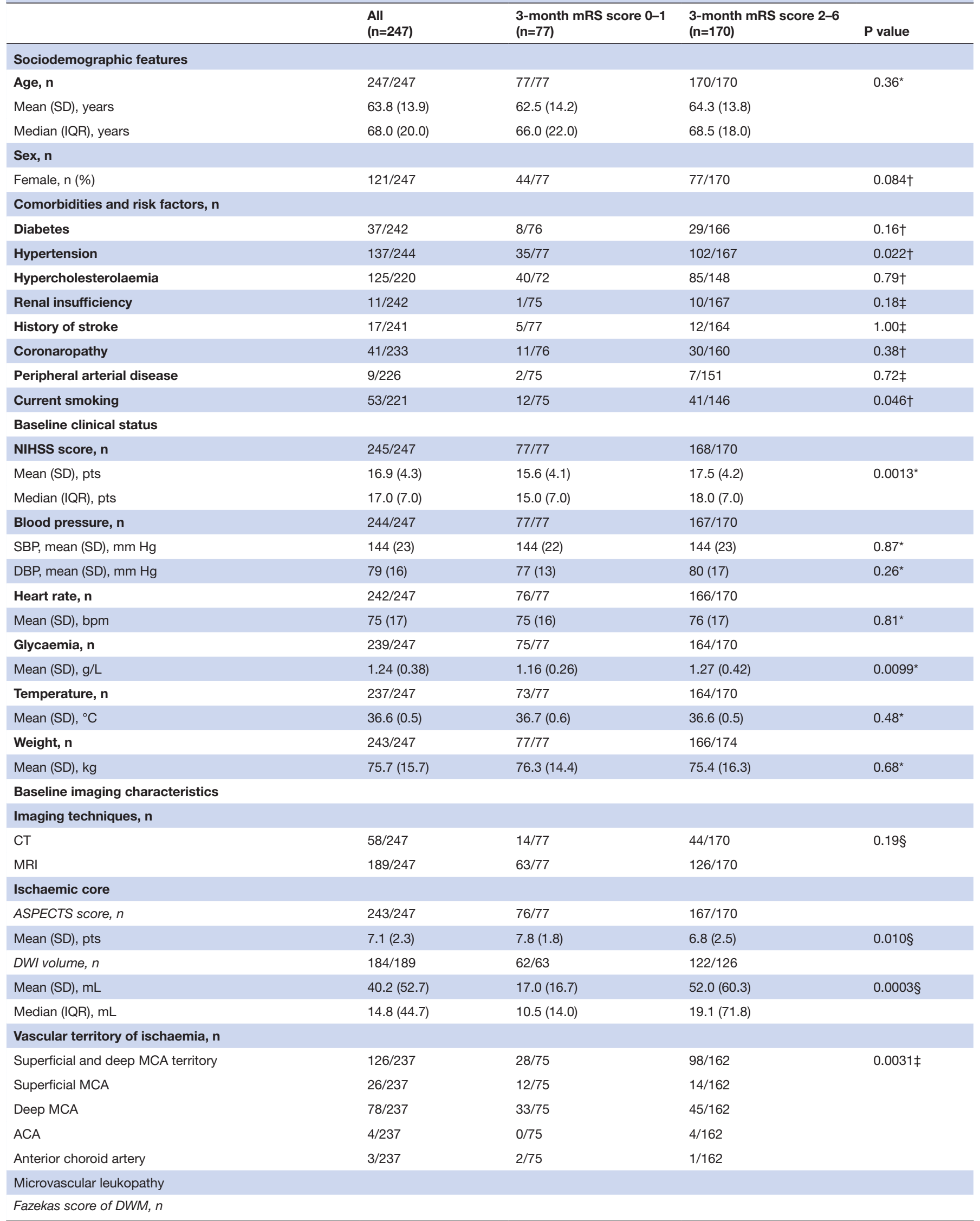


Table 1 Continued

\begin{tabular}{|c|c|c|c|c|}
\hline & $\begin{array}{l}\text { All } \\
(n=247)\end{array}$ & $\begin{array}{l}\text { 3-month mRS score } 0-1 \\
(n=77)\end{array}$ & $\begin{array}{l}\text { 3-month mRS score } 2-6 \\
(n=170)\end{array}$ & $P$ value \\
\hline Absence & $73 / 183$ & $30 / 61$ & $43 / 122$ & $0.24 \ddagger$ \\
\hline Punctuate foci & $65 / 183$ & $20 / 61$ & $45 / 122$ & \\
\hline Beginning confluence & 29/183 & $6 / 61$ & 23/122 & \\
\hline Large confluent areas & $16 / 183$ & $5 / 61$ & $11 / 122$ & \\
\hline \multicolumn{5}{|l|}{ Thrombus } \\
\hline \multicolumn{5}{|l|}{ Occlusion site, $n$} \\
\hline C1 & $39 / 240$ & $4 / 76$ & $35 / 164$ & $0.0017+9$ \\
\hline M1 & $199 / 240$ & $71 / 76$ & $128 / 164$ & \\
\hline M2 & $2 / 240$ & $1 / 76$ & $1 / 164$ & \\
\hline \multicolumn{5}{|l|}{ HMCAS/SVS, $n$} \\
\hline Presence versus absence, $n$ & $176 / 234$ & $55 / 75$ & $121 / 159$ & $0.65 \dagger$ \\
\hline Length, mean (SD), mm & $14.3(10.7)$ & $11.3(8.3)$ & $15.7(11.4)$ & $0.0008 \S$ \\
\hline Clot burden score, mean (SD), pts & $7.0(1.8)$ & $7.5(1.5)$ & $6.8(1.9)$ & $0.0016 \S$ \\
\hline \multicolumn{5}{|l|}{ Mismatch } \\
\hline ASPECT-FVH score, $n$ & $151 / 189$ & $51 / 63$ & $100 / 126$ & $0.74 \S$ \\
\hline Mean (SD), pts & $3.6(1.1)$ & $3.5(1.0)$ & $3.6(1.1)$ & \\
\hline Median (IQR), pts & $4.0(1.0)$ & $4.0(1.0)$ & $4.0(1.0)$ & \\
\hline \multicolumn{5}{|l|}{ FVH/DWI mismatch } \\
\hline Presence versus absence, $n$ & $135 / 177$ & $53 / 61$ & $82 / 116$ & $0.016 \dagger$ \\
\hline \multicolumn{5}{|l|}{ Care workflow time } \\
\hline Onset-to-Imaging time, $n$ & $242 / 247$ & $76 / 77$ & $166 / 170$ & \\
\hline Mean (SD), min & $116(43)$ & $110.6(50.8)$ & $119.0(39.0)$ & $0.20^{\star}$ \\
\hline Onset-to-thrombolysis time, $n$ & $245 / 247$ & $77 / 77$ & $168 / 170$ & \\
\hline Mean (SD), min & $153(40)$ & $142.2(37.4)$ & $158.0(41.0)$ & $0.0042^{*}$ \\
\hline MRI-to-thrombolysis time, $n$ & $241 / 247$ & $76 / 77$ & $165 / 170$ & \\
\hline Mean (SD), $\min$ & $40(20)$ & $39.4(20.6)$ & $40.1(19.4)$ & $0.81^{*}$ \\
\hline \multicolumn{5}{|c|}{ 24-hour clinical and radiological features } \\
\hline NIHSS score, $\mathbf{n}$ & $230 / 247$ & $76 / 77$ & $154 / 170$ & \\
\hline Mean (SD), pts & $11.6(8.2)$ & $3.7(3.5)$ & $15.5(7.0)$ & $<0.0001 \S$ \\
\hline Median (IQR) & $11.0(14.0)$ & $3.0(6.0)$ & $16.0(9.0)$ & \\
\hline ASPECTS, $\mathbf{n}$ & $235 / 247$ & $74 / 77$ & $161 / 170$ & \\
\hline Mean (SD), pts & $5.9(2.7)$ & $7.6(1.6)$ & $5.1(2.8)$ & $<0.0001 \S$ \\
\hline \multicolumn{5}{|c|}{ Haemorrhagic classification (SITS-MOST), n } \\
\hline Absence & $163 / 236$ & $58 / 74$ & $105 / 162$ & $0.27 \ddagger$ \\
\hline Haemorrhagic infarction 1 & $26 / 236$ & $7 / 74$ & $19 / 162$ & \\
\hline Haemorrhagic infarction 2 & $26 / 236$ & $5 / 74$ & $21 / 162$ & \\
\hline Parenchymal haemorrhage 1 & $11 / 236$ & $3 / 74$ & $8 / 162$ & \\
\hline Parenchymal haemorrhage 2 & $10 / 236$ & $1 / 74$ & $9 / 162$ & \\
\hline
\end{tabular}

3-month excellent outcome after IVT alone was defined as a mRS score $\leq 1$

* Statistical analysis was performed with the Student's t-test.

$\dagger \chi^{2}$ test.

†Fisher's exact test.

§Kruskal-Wallis test.

IComparison between $\mathrm{C} 1$ segment and M1/M2 segment.

ACA, anterior cerebral artery; ASPECT-FVH score (0-6), extent of FLAIR vascular hyperintensities based on ASPECTS territories and without counting insula (higher is better);

ASPECTS (0-10), Alberta Stroke Programme Early CT score (higher is better); C1, distal intracranial portion of internal carotid artery; DBP, diastolic blood pressure; DWI volume, diffusion-weighted imaging infarct volume; DWM, deep white matter; FVH/DWI mismatch, FLAIR vascular hyperintensities and diffusion-weighted imaging infarct hyperintensity mismatch; HMCAS, hyper-dense middle cerebral artery sign on CT; M1, first segment of the middle cerebral artery; M2, branches downstream of M1 segment of the middle cerebral artery; MCA, middle cerebral artery; mRS, modified Rankin Scale; NIHSS score (0-42), National Institutes of Health Stroke Scale score; pts, patients; SBP, systolic blood pressure; SITS-MOST, Safe Implementation of Thrombolysis in Stroke MOnitoring STudY; SVS, susceptibility vessel sign on MRI; clot burden score (0-10): higher is better.

259 patients, 247 were included in our subgroup analysis after excluding 12 patients because of THRACE exclusion criteria $(n=5$ patients with cervical internal carotid artery occlusion or history of carotid surgery), absence of intracranial anterior circulation occlusion $(n=2$ basilar artery occlusion or other) and lost to follow-up $(n=5$ missing 3-month mRS score) (figure 1). Moreover, the 24-hour NIHSS score was available for 230/247 patients. 
The mean (SD) age was 63.8 (13.9) years and the male/ female sex ratio 1.04. A total of $77 / 247$ (31.2\%) patients had an excellent 3-month outcome.

Before multiple imputations, cohort description and bivariate analysis were disclosed in table 1 .

After multiple imputations, the bivariate analysis showed the probability of 3-month excellent outcome after IVT alone was associated with no history of hypertension $(\mathrm{p}=0.02)$, lower mean glycaemia level $(\mathrm{p}=0.03)$, lower mean NIHSS score $(\mathrm{p}=0.002)$ and shorter mean OTT ( $\mathrm{p}=0.005$ ) (table 2). On imaging, it was associated with smaller infarction volume on DWI $(p<0.002)$, less often a superficial and deep middle cerebral artery infarct $(\mathrm{p}=0.02)$, shorter thrombus length $(\mathrm{p}=0.02$ on MRI, $\mathrm{p}=0.03$ on CT), more frequently M1 occlusion $(\mathrm{p}=0.005)$, higher CBS ( $\mathrm{p}=0.005$ on MRI, $\mathrm{p}=0.046$ on CT) and more commonly FVH/DWI mismatch $(\mathrm{p}=0.02)$ (table 2).

Multivariate analysis allowed for identifying the following factors independently associated with 3-month excellent outcome after IVT alone: no history of hypertension (OR 2.43; 95\% CI 1.74 to $3.38 ; \mathrm{p}=0.007$ ), no current smoking (OR 2.76; 95\% CI 1.79 to 4.26; $\mathrm{p}=0.02$ ), shorter OTT (OR 0.47 per hour increase; $95 \%$ CI 0.23 to 0.78 ; $\mathrm{p}=0.003$ ), smaller DWI volume (OR 0.78 per $10 \mathrm{~mL}$ increase; $95 \%$ CI 0.68 to $0.89 ; \mathrm{p}=0.0004)$, presence of SVS (OR 7.89; 95\% CI 1.65 to 37.78; $\mathrm{p}=0.01$ ) and reduced SVS length (OR 0.87 per mm increase; $95 \%$ CI 0.80 to 0.94 ; $\mathrm{p}=0.001$ ) (table 2). The model allowed for good discrimination, with a C-statistic of 0.79 (95\% CI 0.79 to 0.80$)$ and was well calibrated, with Brier score 0.16 and adjusted $R^{2}$ 0.31 .

The normalised NIHSS score change at 24 hours was independently associated with 3-month mRS score 0-1 (adjusted OR 1.79 per $10 \%$ increase; 95\% CI 1.65 to 1.93 ; $\mathrm{p}<0.0001$; area under the receiver operating characteristic curve $0.93 ; 95 \%$ CI 0.89 to 0.96 ) (table 3). With a normalised NIHSS score change threshold set at $35.7 \%$ and a Youden Index at 0.71 , sensitivity was 0.92 , specificity 0.79 , PPV 0.69 and NPV 0.95. To anticipate a 3-month excellent outcome, the best specificity and PPV were found with SNI (specificity=0.96; PPV=0.88), MNI (specificity=0.86; $\mathrm{PPV}=0.73$ ) or NIHSS score improvement $\geq 50 \%$ (specificity $=0.85$; $\mathrm{PPV}=0.74$ ) (table 3 ).

\section{DISCUSSION}

Our study provides important information about factors associated with success with IVT alone in patients with stroke with LVO of the anterior circulation. High predictors of 3-month mRS score $0-1$ after IVT alone were no medical history of hypertension, no current smoking, reduced OTT, small DWI volume, presence of SVS and short SVS length. In the context of this treatment, this excellent clinical outcome at 3 months can be strongly anticipated by the early NIHSS improvement criteria SNI, MNI and NIHSS improvement of at least $50 \%$.

Factors found associated with 3-month excellent outcome seemed related to time to IVT, thrombus features, effectiveness of leptomeningeal collateral arteries and the resulting seriousness of the infarction before treatment. Current smoking is known to enhance thrombotic effects with increased platelet adherence, endothelial cell damage and the consequent remodelling of parietal vessels. In patients with $\mathrm{LVO}$, these mechanisms prevent the development of leptomeningeal collateral arteries supplying parenchyma. ${ }^{14}{ }^{15}$ Similarly, hypertension would also compromise collateral circulation. ${ }^{16}$

The DWI volume, presence of SVS and SVS length on MRI were the only independent imaging factors associated with the IVT response. Pretreatment infarction volume is an indicator of the seriousness of the stroke and is associated with early and long-term outcome. ${ }^{17} \mathrm{~A}$ lack of leptomeningeal collateral circulation facilitates rapid growth of the ischaemic core. However, the FVH/ DWI mismatch seems not an appropriate surrogate of leptomeningeal collateral arteries, nor the ASPECT-FVH score, in predicting 3-month excellent outcome.

Although patients with a large ischaemic core should not be systematically excluded from reperfusion therapy, they are particularly at risk of unfavourable response after IVT alone. This finding is explained in part by the seriousness of cerebral infarction before treatment restricting neurological recovery in the long term, and by absence or delayed reperfusion at the acute phase. ${ }^{18} 19$

From the occlusion characteristics included in the CBS, SVS length emerged as the most determinant factor. This finding may explain the poor response to IVT with intracranial internal carotid artery occlusion. ${ }^{20}$ Previous studies have observed a threshold of $8 \mathrm{~mm}$ for thrombus length as highly predictive of IVT failure. ${ }^{20}$ Presence of SVS was associated with red blood cell-dominant thrombus and IVT effectiveness. ${ }^{21}$ OTT is also probably a predictor combining greater chance of reperfusion and lower infarction volume with early IVT instauration. ${ }^{22}$

Another issue of this study was to predict optimal response to IVT with excellent outcome at the long term with early clinical examination after treatment. Previous studies have assessed the success of reperfusion mainly by vascular imaging. ${ }^{1}$ Early clinical improvement of patients with stroke with LVO is strongly associated with satisfactory and sustainable reperfusion. ${ }^{23-26}$ Consistently, we found a strong association between early and significant clinical improvement after IVT alone and excellent outcome at the long term. Among the different criteria of NIHSS improvement at 24 hours studied, SNI, MNI and NIHSS improvement of at least $50 \%$ to anticipate the excellent outcome showed good specificity and PPV. Nevertheless, clinical examination to assess NIHSS score in patients with LVO after IVT has to be performed as fast as possible, and must not delay MT.

The strength of our study lies in the large sample of patients prospectively included in the randomised THRACE study, allowing for a robust analysis of predictors of 3-month excellent outcome after IVT alone. The choice of a dichotomous mRS 1 is supported by the need to increasingly refine the prediction of 3-month favourable outcome for patients 
Table 2 Predictors of 3-month excellent outcome after IVT

3-month mRS score 0 -1

( $\mathrm{n}=77 / 247)$

\begin{tabular}{|c|c|c|c|c|c|c|}
\hline & \multicolumn{3}{|c|}{ Bivariate $(\mathrm{n}=247)$} & \multicolumn{3}{|c|}{ Multivariate $(n=247)$} \\
\hline & OR & $95 \% \mathrm{Cl}$ & $P$ value & OR & $95 \% \mathrm{Cl}$ & $P$ value \\
\hline \multicolumn{7}{|l|}{ Sociodemographics features } \\
\hline Sex: male versus female & 0.62 & 0.36 to 1.07 & 0.09 & & & \\
\hline \multicolumn{7}{|l|}{ Comorbidities and risk factors } \\
\hline Current smoking: absence versus presence & 1.86 & 1.30 to 2.66 & 0.083 & 2.76 & 1.79 to 4.26 & 0.019 \\
\hline \multicolumn{7}{|l|}{ Baseline clinical examination } \\
\hline NIHSS score, pts* & 0.90 & 0.84 to 0.96 & 0.0018 & & & \\
\hline Systolic blood pressure, $\mathrm{mm} \mathrm{Hg}^{*}$ & 1.00 & 0.99 to 1.01 & 0.91 & & & \\
\hline Hour ${ }^{\star}$ & 0.53 & 0.35 to 0.83 & 0.0048 & 0.47 & 0.23 to 0.78 & 0.0033 \\
\hline \multicolumn{7}{|l|}{ Imaging features } \\
\hline Imaging technique: CT versus MRI & 0.64 & 0.32 to 1.25 & 0.19 & & & \\
\hline DWI volume, $10 \mathrm{~mL} † \ddagger$ & 0.85 & 0.77 to 0.94 & 0.0016 & 0.78 & 0.68 to 0.89 & 0.0004 \\
\hline Infarct territory & & & 0.0033 & & & \\
\hline Superficial MCA & \multicolumn{3}{|c|}{ Reference } & & & \\
\hline Deep MCA & 0.86 & 0.35 to 2.08 & 0.73 & & & \\
\hline Superficial and deep MCA & 0.34 & 0.14 to 0.81 & 0.015 & & & \\
\hline Other & 0.41 & 0.07 to 2.23 & 0.30 & & & \\
\hline MRI, pts* & 1.26 & 1.07 to 1.47 & 0.0053 & & & \\
\hline \multicolumn{7}{|l|}{ HMCAS/SVS } \\
\hline HMCAS: presence versus absence & 0.87 & 0.25 to 2.99 & 0.83 & 0.80 & 0.22 to 2.99 & 0.74 \\
\hline SVS: presence versus absence & 0.84 & 0.40 to 1.77 & 0.65 & 7.89 & 1.65 to 37.78 & 0.0097 \\
\hline FVH/DWI mismatch: yes versus noł & 2.71 & 1.19 to 6.20 & 0.018 & & & \\
\hline ASPECT-FVH score, pts* $\ddagger$ & 1.09 & 0.93 to 1.27 & 0.31 & & & \\
\hline \multicolumn{7}{|l|}{ DWM Fazekas score, ptsł } \\
\hline $\mathrm{CT}, \mathrm{pts}^{*}$ & 0.68 & $<0.01$ to $>100$ & 0.99 & & & \\
\hline MRI, pts* & 0.79 & 0.56 to 1.10 & 0.16 & & & \\
\hline
\end{tabular}

3-month excellent outcome after IVT defined by a 3-month mRS score $\leq 1$.

All ORs are calculated for 3-month mRS score $\leq 2$.

Bold values shows $p<0.05$.

${ }^{*}$ ORs express the risk variation for a unit increase of the variable.

tORs express the risk variation for $10 \mathrm{~mL}$ increase in the ischaemic core volume on DWI.

¥Nested effect is adjusted on the nesting characteristics, that is, imaging type, to consider effect differently in CT and in MRI.

ASPECTS-FVH score, Alberta Stroke Programme Early CT score and extent of FLAIR vascular hyperintensities (0-6); C1, distal internal carotid artery; clot burden score (0-10); DWI, diffusion-weighted imaging; DWI volume, ischaemic core volume on DWI; DWM Fazekas score, deep white matter Fazekas score (0-3); FVH/DWI mismatch, FLAIR vascular hyperintensity and DWI infarct hyperintensity mismatch; HMCAS/SVS, hyper-dense MCA sign on CT or susceptibility vessel sign on T2*-MRI; IVT, intravenous thrombolysis; M1, first segment of MCA; MCA, middle cerebral artery; mRS, modified Rankin Scale; NIHSS, National Institutes of Health Stroke scale; OTT, onset-to-treatment time; pts, patients. 


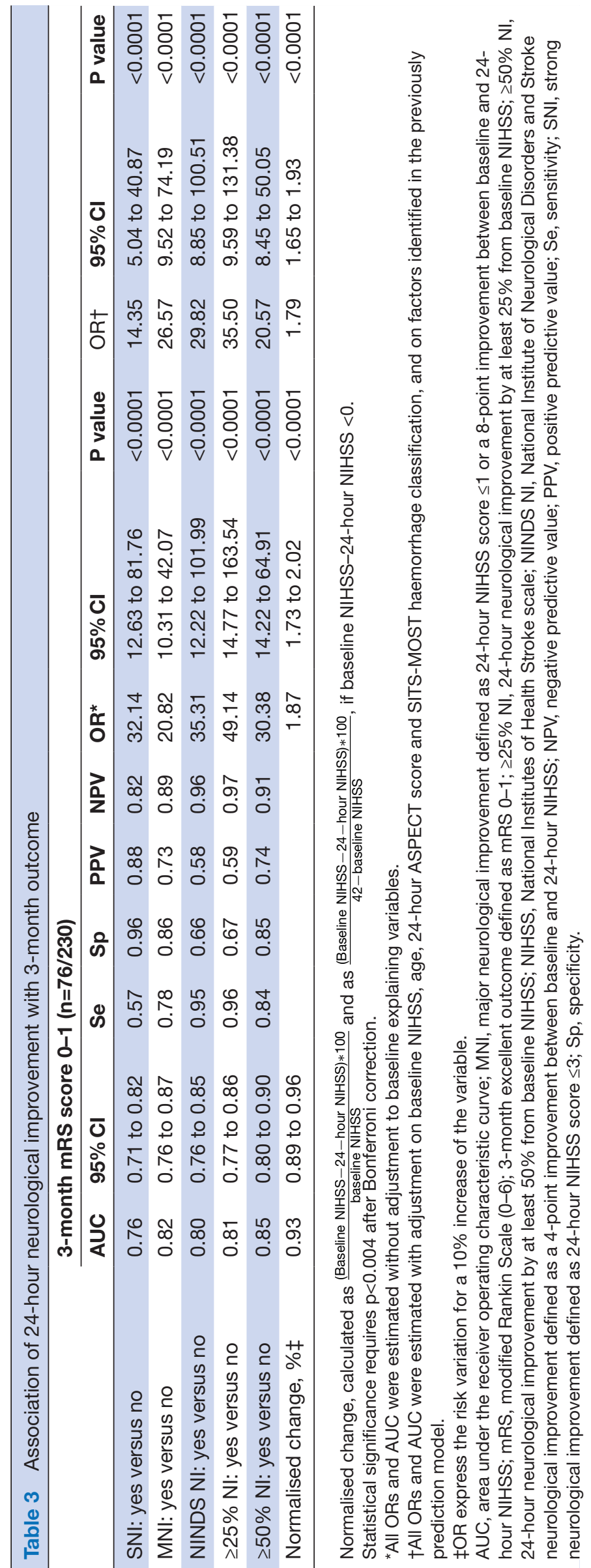


who benefit from better adapted and more efficient revascularisation strategies. However, some limitations deserve to be mentioned. First, some important data—such as inflammatory and clotting parameters, or previous use of antiplatelet therapy-were not collected. The earliest NIHSS score assessment after treatment was at 24 hours in our study, but studies report that reperfusion, and consequent NIHSS improvement, occurs almost exclusively during the first 2 hours after IVT instauration. However, this estimation can be considered reliable because the patient clinical state was found quite similar between 1 and 24 hours after treatment. ${ }^{27}$ We merged data from patients mostly examined with MRI and less with CT but took into account qualitative differences between these imaging techniques in the multivariate analysis.

Predicting the benefit of IVT for patients with LVO to achieve optimal reperfusion remains of high interest. This issue seems different following admission centre. For patients with LVO admitted in a centre without MT capability, IVT represents the first-line treatment in reperfusion strategy. Clinical and radiological criteria associated with optimal response to IVT allow identifying a patient subgroup with high probability to achieve reperfusion during transfer, before planned MT. They can be considered as arguments to help practitioners in decision-making to implement IVT in patients with initial contraindications, nowadays highly debated as elderly, medical history of cerebral haemorrhage, and demonstrated penumbra beyond the time window of 4.5 hours. ${ }^{4}$ For patients with LVO admitted in MT capable centres, bridging therapy (including IVT and MT) remains the gold standard. But, relevance of IVT is questioned following recent results from DIRECT-MT (Direct Intraarterial Thrombectomy in Order to Revascularize Acute Ischemic Stroke Patients with Large Vessel Occlusion Efficiently in Chinese Tertiary Hospitals) and DEVT (Effect of Endovascular Treatment Alone vs Intravenous Alteplase Plus Endovascular Treatment on Functional Independence in Patients With Acute Ischemic Stroke) trials suggesting MT alone was not non-inferior to bridging therapy. ${ }^{28} 29$ However for patients who received IVT in DIRECT-MT, higher frequency of cerebral reperfusion was observed, despite high median OTT. More, non-inferiority was not confirmed by the SKIP trial. ${ }^{30}$ Finally, knowledge about factors predicting cerebral reperfusion achievement or failure after IVT could guide research towards new therapeutic strategies. Clinical improvement with reduction of haemorrhagic risk have been reported with alteplase doses lower than the $0.9 \mathrm{mg} / \mathrm{kg}$ standard dose, suggesting possible dosage adjustment following patient and stroke characteristics. ${ }^{31}$ On the contrary, subgroup of patients with low probability of reperfusion could be candidate to alternative or additional thrombolytics to alteplase. In this way, the EXTEND-IA TNK (Tenecteplase versus Alteplase before Endovascular Therapy for Ischemic Stroke) trial observed a higher rate of reperfusion in patients with LVO after infusion with tenecteplase than alteplase before $\mathrm{MT}^{32}$ Safety of glenzocimab, in addition to alteplase at the acute phase of cerebral infarction, is currently assessed. ${ }^{33}$

\section{CONCLUSIONS}

Predictors of success with IVT alone in LVO stroke are no medical history of hypertension, no current smoking, reduced OTT, small DWI volume, presence of SVS and short SVS length. These predictors may contribute to identifying patients with high probability to achieve optimal cerebral reperfusion after IVT, and help decision-making in therapeutic strategy. This hypothesis and inherent 3-month excellent outcome can strongly be anticipated by early and significant improvement of the NIHSS score.

Collaborators THRACE investigators: Alain Bonafé, Xavier Leclerc, Nelly Agrinier, Serge Bakchine, Flore Baronnet, Marine Beaumont, Yannick Bejot, Jerome Berge, Marc Bintner, Romain Bourcier, Tae Hee Cho, Frédéric Clarencon, Julien Cogez, Charlotte Cordonnier, Christian Denier, Anne Laure Derelle, Olivier Detante, Xavier Ducrocq, Anthony Faivre, Anne Ferrier, Laetitia Gimenez, Sophie Godard, Benoit Guillon, Emmanuel Houdart, Bertrand Lapergue, Jean-Louis Mas, Thierry Moulin, Mariano Musacchio, Olivier Naggara, Jean Philippe Neau, Michael Obadia, Anne Pasco-Papon, Michel Piotin, Laurent Pierot, Helene Raoult, Frederic Ricolfi, Thomas Ronziere, Guillaume Saliou, Igor Sibon, Sebastien Soize, Jacques Sedat, Christian Stapf, Laurent Suissa, Marie Tisserand, Francis Turjman, Stephane Velasco

Contributors NR-C and SR collected data, performed analysis and drafted the manuscript. BG, SB and FG critically revised the manuscript for substantial changes. MS performed statistical analysis. FZ, YX, LH, GM and CO critically revised the manuscript. All authors have approved the submitted manuscript.

Funding The authors have not declared a specific grant for this research from any funding agency in the public, commercial or not-for-profit sectors.

Competing interests None declared.

Patient consent for publication Not required.

Ethics approval The study is a subgroup analysis of the THRACE trial having received the required legal approval from the "Comité de Protection des Personnes III", Nord Est Ethics Committee, and the research boards of the participating centres with 2009-A00753-54. All patients or their legal representatives provided written informed consent.

Provenance and peer review Not commissioned; externally peer reviewed. Data availability statement Data are available on reasonable request. Only data that are relevant for the main objective of this ancillary study were available from the THRACE trial in agreement with the principal investigator of the trial. Individual de-identified participant data were shared following the explanation of the main objective and the statistical analysis. Data are available on reasonable request to SR (s.richard@chru-nancy.fr).

Author note The work has been carried out at Nancy Regional University Hospital, France.

Open access This is an open access article distributed in accordance with the Creative Commons Attribution Non Commercial (CC BY-NC 4.0) license, which permits others to distribute, remix, adapt, build upon this work non-commercially, and license their derivative works on different terms, provided the original work is properly cited, appropriate credit is given, any changes made indicated, and the use is non-commercial. See: http://creativecommons.org/licenses/by-nc/4.0/.

\section{ORCID iDs}

Marc Soudant http://orcid.org/0000-0001-5814-6924

Sébastien Richard http://orcid.org/0000-0002-0945-5656

\section{REFERENCES}

1 Seners P, Turc G, Maïer B. Incidence and predictors of early recanalization after intravenous thrombolysis: a systematic review and meta-analysis. Stroke 2016;47:2409-12.

2 National Institute of Neurological Disorders and Stroke rt-PA Stroke Study Group. Tissue plasminogen activator for acute ischemic stroke. N Engl J Med 1995;333:1581-8. 
3 Hacke W, Kaste M, Bluhmki E, et al. Thrombolysis with alteplase 3 to 4.5 hours after acute ischemic stroke. $N$ Engl J Med 2008;359:1317-29.

4 Berge E, Whiteley W, Audebert H, et al. European stroke organisation (ESO) guidelines on intravenous thrombolysis for acute ischaemic stroke. Eur Stroke J 2021;6:I-LXII.

5 Turc G, Apoil M, Naggara O, et al. Magnetic resonance ImagingDRAGON score: 3-month outcome prediction after intravenous thrombolysis for anterior circulation stroke. Stroke 2013;44:1323-8.

6 Baek JH, Kim K, Lee Y-B, et al. Predicting stroke outcome using clinical- versus imaging-based scoring system. J Stroke Cerebrovasc Dis 2015;24:642-8.

7 Hernández-Pérez M, Pérez de la Ossa N, Aleu A, et al. Natural history of acute stroke due to occlusion of the middle cerebral artery and intracranial internal carotid artery. J Neuroimaging 2014;24:354-8.

8 Bracard S, Ducrocq X, Mas JL, et al. Mechanical thrombectomy after intravenous alteplase versus alteplase alone after stroke (THRACE): a randomised controlled trial. Lancet Neurol 2016;15:1138-47.

9 Legrand L, Tisserand M, Turc G, et al. Fluid-Attenuated inversion recovery vascular Hyperintensities-Diffusion-Weighted imaging mismatch identifies acute stroke patients most likely to benefit from recanalization. Stroke 2016;47:424-7.

10 Nave AH, Kufner A, Bücke P, et al. Hyperintense vessels, collateralization, and functional outcome in patients with stroke receiving endovascular treatment. Stroke 2018;49:675-81.

11 Balucani C, Levine SR, Khoury JC, et al. Acute ischemic stroke with very early clinical improvement: a national Institute of neurological disorders and stroke recombinant tissue plasminogen activator stroke trials exploratory analysis. J Stroke Cerebrovasc Dis 2016;25:894-901.

12 Grotta JC, Welch KM, Fagan SC, et al. Clinical deterioration following improvement in the NINDS rt-PA stroke trial. Stroke 2001;32:661-8.

13 Wahlgren N, Ahmed N, Dávalos A, et al. Thrombolysis with alteplase for acute ischaemic stroke in the safe implementation of thrombolysis in Stroke-Monitoring study (SITS-MOST): an observational study. Lancet 2007;369:275-82.

14 Shuaib A, Butcher K, Mohammad AA, et al. Collateral blood vessels in acute ischaemic stroke: a potential therapeutic target. Lancet Neurol 2011;10:909-21.

15 Béjot $Y$, Jacquin A, Daubail B, et al. Smoking status and severity of ischemic stroke. A population-based study. Eur Neurol 2014;71:59-64.

16 Chan S-L, Sweet JG, Bishop N, et al. Pial collateral reactivity during hypertension and aging: understanding the function of collaterals for stroke therapy. Stroke 2016;47:1618-25.

17 Barrett KM, Ding YH, Wagner DP, et al. Change in diffusion-weighted imaging infarct volume predicts neurologic outcome at 90 days: results of the acute stroke accurate prediction (ASAP) trial serial imaging substudy. Stroke 2009;40:2422-7.

18 Gautheron V, Xie Y, Tisserand M, et al. Outcome after reperfusion therapies in patients with large baseline diffusion-weighted imaging stroke lesions: a THRACE trial (mechanical thrombectomy after intravenous alteplase versus alteplase alone after stroke) subgroup analysis. Stroke 2018;49:750-3.

19 Humpich M, Singer OC, du Mesnil de Rochemont R, et al. Effect of early and delayed recanalization on infarct pattern in proximal middle cerebral artery occlusion. Cerebrovasc Dis 2006;22:51-6.

20 Riedel $\mathrm{CH}$, Zimmermann P, Jensen-Kondering U, et al. The importance of size: successful recanalization by intravenous thrombolysis in acute anterior stroke depends on thrombus length. Stroke 2011;42:1775-7.

21 Choi MH, Park GH, Lee JS, et al. Erythrocyte fraction within retrieved thrombi contributes to thrombolytic response in acute ischemic stroke. Stroke 2018;49:652-9.

22 Fonarow GC, Zhao X, Smith EE, et al. Door-to-needle times for tissue plasminogen activator administration and clinical outcomes in acute ischemic stroke before and after a quality improvement initiative. JAMA 2014;311:1632-40.

$23 \mathrm{Rha} J-\mathrm{H}$, Saver JL. The impact of recanalization on ischemic stroke outcome: a meta-analysis. Stroke 2007;38:967-73.

24 Khatri P, Neff J, Broderick JP, et al. Revascularization end points in stroke interventional trials: recanalization versus reperfusion in IMS-I. Stroke 2005;36:2400-3.

25 Zaidat OO, Yoo AJ, Khatri P, et al. Recommendations on angiographic revascularization grading standards for acute ischemic stroke: a consensus statement. Stroke 2013;44:2650-63.

26 Eilaghi A, Brooks J, d'Esterre C, et al. Reperfusion is a stronger predictor of good clinical outcome than recanalization in ischemic stroke. Radiology 2013;269:240-8.

27 Takagi T, Kato T, Sakai H, et al. Early neurologic improvement based on the National Institutes of health stroke scale score predicts favorable outcome within 30 minutes after undergoing intravenous recombinant tissue plasminogen activator therapy. J Stroke Cerebrovasc Dis 2014;23:69-74.

28 Yang $P$, Zhang $Y$, Zhang $L$, et al. Endovascular thrombectomy with or without intravenous alteplase in acute stroke. N Engl J Med 2020;382:1981-93

29 Zi W, Qiu Z, Li F, et al. Effect of endovascular treatment alone vs intravenous alteplase plus endovascular treatment on functional independence in patients with acute ischemic stroke: the DEVT randomized clinical trial. JAMA 2021;325:234-43.

30 Suzuki K, Matsumaru Y, Takeuchi M, et al. Effect of mechanical thrombectomy without vs with intravenous thrombolysis on functional outcome among patients with acute ischemic stroke: the SKIP randomized clinical trial. JAMA 2021;325:244-53.

31 Dong $\mathrm{Y}$, Han $\mathrm{Y}$, Shen $\mathrm{H}$, et al. Who may benefit from lower dosages of intravenous tissue plasminogen activator? Results from a cluster data analysis. Stroke Vasc Neurol 2020;5:348-52.

32 Campbell BCV, Mitchell PJ, Churilov L, et al. Tenecteplase versus alteplase before thrombectomy for ischemic stroke. $N$ Engl J Med 2018;378:1573-82.

33 Renaud L, Lebozec K, Voors-Pette C, et al. Population pharmacokinetic/pharmacodynamic modeling of Glenzocimab (ACT017) a glycoprotein VI inhibitor of collagen-induced platelet aggregation. J Clin Pharmacol 2020;60:1198-208. 